Received: 2021/07/03, Revised: 2021/08/28, Accepted: 2021/09/06, Published: 2021/09/30 (๑2021 Morteza Khodaee et al.; Licence Physical Activity and Nutrition. This is an open access article distributed under the terms of the creative commons attribution license (https://creativecommons.org/licenses/by-nc/2.0/), which permits unrestricted use, distribution, and reproduction in any medium, provided the orginal work is properly cited. ${ }^{*}$ Corresponding author : Morteza Khodaee, MD, MPH

University of Colorado School of Medicine, Department of Family Medicine and Orthopedics, Division of Sports Medicine, AFW Clinic, 3055 Roslyn Street, Denver, CO 80238 , USA.

Tel: 720-848-9056 / Fax: 720-848-9002

E-mail: Morteza.khodaee@cuanschutz.edu

@2021 The Korean Society for Exercise Nutrition
[Purpose] Exercise-associated hyponatremia (EAH) is a well-known condition among endurance athletes at low altitudes. The incidence of EAH during ultramarathons at high altitudes warrants further investigation. This prospective observational study was conducted on the participants of the Leadville Trail 100 run, a 161$\mathrm{km}$ race held at a high altitude $(2,800 \mathrm{~m}-3,840 \mathrm{~m})$.

[Methods] Venous blood samples were collected before and immediately after the race. The participants completed an electronic survey after the race. Our main outcome measure was the post-race serum sodium $\left(\left[\mathrm{Na}^{+}\right]\right)$level.

[Results] Of the 672 athletes who started the race, 351 $(52 \%)$ successfully completed the event within the 30 hour cut-off. Post-race blood samples were collected from 84 runners ( 66 finishers). Both pre- and post-race blood samples were collected from 37 participants. Twenty percent of the post-race participants had EAH. Only one post-race participant had a [ $\left.\mathrm{Na}^{+}\right]$level of $<130$ $\mathrm{mmol} / \mathrm{L}$. All participants with EAH were asymptomatic. One participant had an abnormal pre-race $\left[\mathrm{Na}^{+}\right]$level (134 mmol/L). Female participants had a significantly higher rate of EAH than male participants ( $40 \%$ vs. $16 \% ; p=0.039$ ). Age, body mass index, weight changes, race completion status, nonsteroidal anti-inflammatory drug use, and urine specific gravity were not associated with the development of EAH. Lower postrace $\left[\mathrm{Na}^{+}\right]$levels were associated with higher serum creatine kinase values $\left(R^{2}=0.1, p<0.005\right)$.

[Conclusion] High altitude (3,840 m peak) does not appear to enhance the incidence of EAH after an ultramarathon footrace. This suggests that ambient temperature (low temperatures reduce risk), sex (female predilection), endurance running, and overhydration are more prominent risk factors for EAH than high altitude.

[Key words] ultra-endurance, mountain, running, serum electrolytes

\section{Incidence of exercise-associated hyponatremia during a high-altitude 161-km ultramarathon}

\author{
Morteza Khodaee $^{1^{*}} /$ Anahita Saeedi $^{2}$ / \\ Christine Harris-Spinks ${ }^{3}$ / Tamara Hew-Butler ${ }^{4}$
}

\author{
1. University of Colorado School of Medicine, Department of Family Medicine and Orthopedics, Denver, USA \\ 2. University of Massachusetts, Department of Biostatistics, MA, USA \\ 3. Franciscan Medical Clinic, Auburn, WA, USA \\ 4. Division of Kinesiology, Wayne State University, Michigan, USA
}

\section{INTRODUCTION}

An ultramarathon is defined as any race longer than the classic marathon distance of $42.2 \mathrm{~km}$. As such, the popularity of ultramarathons has increased significantly over the past few decades ${ }^{1,2}$. Our understanding of the physiological effects of strenuous endurance exercise continues to improve, although significant gaps in our knowledge remain. One of the most serious and preventable medical derangements seen after endurance sports is exercise-associated hyponatremia (EAH). EAH is biochemically defined as a serum sodium $\left(\left[\mathrm{Na}^{+}\right]\right)$concentration level $<135 \mathrm{mmol} / \mathrm{L}$, documented during or immediately after exercise $\mathrm{e}^{3-5}$. The EAH has been reported to occur in $<1-51 \%$ of the participants after different sporting events $^{3-7}$. EAH can be asymptomatic or symptomatic, with life-threatening complications, such as seizures and death in severe cases, $3,5,8,9$. The risk factors for developing EAH include the duration of exercise, specific sporting activity, female sex, high ambient temperature, overdrinking, and possibly nonsteroidal anti-inflammatory drug (NSAID) use $\mathrm{e}^{3,4,7,10}$. The incidence of EAH is higher in ultra-endurance events than in short-duration events ${ }^{6,7,11,12}$, with more reports of EAH after ultramarathons and triathlons than after cycling and running marathons $\mathrm{s}^{7,13,14}$

The effects of endurance exercise on other electrolytes seem minor ${ }^{15}$; however, further study is required. Additionally, the effects of moderate to high altitudes on EAH and electrolyte balance remain underexplored. A previous investigation performed on 11 marathon runners demonstrated that serum $\left[\mathrm{Na}^{+}\right]$was significantly lower (approximately $132 \mathrm{mmol} / \mathrm{L}$ ) after a marathon performed at an altitude of $2,650 \mathrm{~m}$ than at sea level (approximately $145 \mathrm{mmol} / \mathrm{L})^{16}$. Symptomatic EAH has also been confirmed in an otherwise healthy hiker during a 3-day hike above 2,400 $\mathrm{m}^{9}$. EAH may be exacerbated at high altitudes from altitude-mediated, non-osmotic stimulation of the antidiuretic hormone, arginine vasopressin $(A V P)^{16}$. Non-osmotic AVP stimulation would hypothetically increase the risk of EAH in athletes from a syndrome of inappropriate secretion of antidiuretic hormone-like pathological mechanism ${ }^{17}$; although, this pathophysiological mechanism has been challenged by other studies ${ }^{18}$. Additionally, hypoxia may exacerbate the development of EAH encepha- 
lopathy, which puts athletes at an enhanced risk of more dire EAH-related complications ${ }^{19}$. Therefore, the primary purpose of this study was to investigate the incidence of EAH in the participants of the Leadville Trail 100, a high-altitude ultramarathon footrace. The secondary purpose was to evaluate additional risk factors for the development of EAH in this population. We hypothesized that the incidence of EAH would increase at the Leadville Trail 100, compared with the incidence of EAH at ultramarathon footraces conducted at lower altitudes because of the potential for altitude-induced non-osmotic AVP secretion exacerbating fluid retention (and dilutional EAH).

\section{METHODS}

The study was conducted during the Leadville Trail 100 run near Leadville, Colorado, in August 2014. We used data from weather stations near the course to determine the meteorological conditions during the race. At the start (4:00 AM) of the race on August 16, 2014, the temperature was $2^{\circ} \mathrm{C}$ with light wind. The temperature rose to approximately $22^{\circ} \mathrm{C}$, and the wind speed was approximately $16 \mathrm{~km} / \mathrm{h}$ by late afternoon. There was no precipitation and the average humidity was $57 \%$ (range: $22-92 \%$ ). Runners had to pass the finish line within $30 \mathrm{~h}$ to successfully complete the race. The weather was similar on August 17, 2014. All runners were weighed using digital scales a day before the race at the 50-mile aid station and the finish line. The study was open to all runners who were interested in participating. A total of 111 runners volunteered to participate in the study. Of the samples collected, 64 were pre-race and 84 were post-race samples. We collected both pre- and post-race blood samples from 37 runners. Information on urine analysis has been published elsewhere ${ }^{20}$. There was no compensation for participating in the study; however, the athletes were informed about their test results. We recruited participants during the pre-race medical check-in (a day before the race) meeting and at the post-race finish aid station. Blood samples were collected on the morning of the day before the race and at the finish line to determine whether the runners finished the race or dropped out of the race. However, we collected blood samples from a substantial number of non-finishers at the 50-mile aid station, as it was the major drop-out location. Blood samples were collected within 30 min after the completion of the race or when the participants dropped out at the 50-mile aid station. For runners who dropped out in the second half of the race and participated in the study, blood collection occurred within $2 \mathrm{~h}$ of dropping out. A total of $3 \mathrm{~mL}$ of blood was drawn into heparinized tubes through the antecubital vein while the participant was seated. The samples were refrigerated and transported to the University of Colorado Hospital laboratory within 24 h. Blood test analysis included analysis of a comprehensive metabolic panel (e.g., serum electrolytes, serum renal and liver function tests) and serum creatine kinase (CK) levels.

Runners' characteristics, medical history, and race performance were available through online pre- and post-race questionnaires and other studies associated with the race. Runners who provided post-race blood samples were evaluated by clinicians at the finish line or other medical aid stations. All runners who provided blood samples were contacted for any symptoms through an electronic survey 1-2 weeks after the race. More information on the methodology and other analyses of this study are available elsewhere ${ }^{21,22}$. The Colorado Multiple Institutional Review Board and the Leadville Race Series approved the study. The runners provided written informed consent before participating in this study.

Statistical analyses were conducted using IBM SPSS (version 26.0, SPSS, Inc., Chicago, IL, USA). Descriptive statistics were used to examine the frequency, mean, median, and range of all variables. As $\left[\mathrm{Na}^{+}\right]$and other electrolytes were not normally distributed (one-sample Kolmogorov-Smirnov test was $p<0.001$ ), non-parametric (Wilcoxon and Mann-Whitney U tests) analyses were performed. Bivariate nominal comparisons were made using the chisquare test. A Wilcoxon matched-pairs test for paired samples was used to assess the impact of the race on the data obtained in the two predetermined moments (pre- and postrace). Statistical significance was set at $p<0.05$. A binary multiple logistic regression was used to evaluate the associations between several variables and the presence of EAH.

\section{RESULTS}

Of the 669 athletes who started the ultramarathon, 352 $(53 \%)$ successfully completed the race in $<30 \mathrm{~h}$ (Table 1 and Fig. 1). Most runners were males (84\%). We collected both

Table 1. Demographic information of the participants.

\begin{tabular}{|c|c|c|c|c|}
\hline Participant characteristics & $\begin{array}{l}\text { Participants with } \\
\text { pre-race samples } \\
\qquad(n=64)\end{array}$ & $\begin{array}{l}\text { Participants with } \\
\text { post-race samples } \\
\qquad(n=84)\end{array}$ & $\begin{array}{l}\text { Participants with } \\
\text { both pre- and post- } \\
\text { race samples ( } n=37 \text { ) }\end{array}$ & $\begin{array}{c}\text { All runners } \\
\text { in the race } \\
(n=669)\end{array}$ \\
\hline Age (year); mean \pm SD* & $42.7 \pm 9.6$ & $42.1 \pm 9.0$ & $43.1 \pm 10.0$ & $40.3 \pm 8.6$ \\
\hline \multicolumn{5}{|l|}{ Sex; $n(\%)$} \\
\hline Male & $51(79.7)$ & $69(82.1)$ & $29(78.4)$ & $560(83.7)$ \\
\hline Female & $13(20.3)$ & $15(17.9)$ & $8(21.6)$ & $109(16.3)$ \\
\hline BMI $\left(\mathrm{kg} / \mathrm{m}^{2}\right) ;$ mean \pm SD & $23.3 \pm 2.4$ & $22.8 \pm 2.1$ & $22.7 \pm 2.4$ & $23.4 \pm 2.3$ \\
\hline \multicolumn{5}{|l|}{ Race completion status; n (\%) } \\
\hline Finished & $30(46.9)$ & $66(78.6)$ & $28(75.7)$ & $352(52.6)$ \\
\hline Did not finish & $34(53.1)$ & $18(21.4)$ & $9(24.3)$ & $317(47.4)$ \\
\hline
\end{tabular}

SD, standard deviation; BMI, body mass index. 


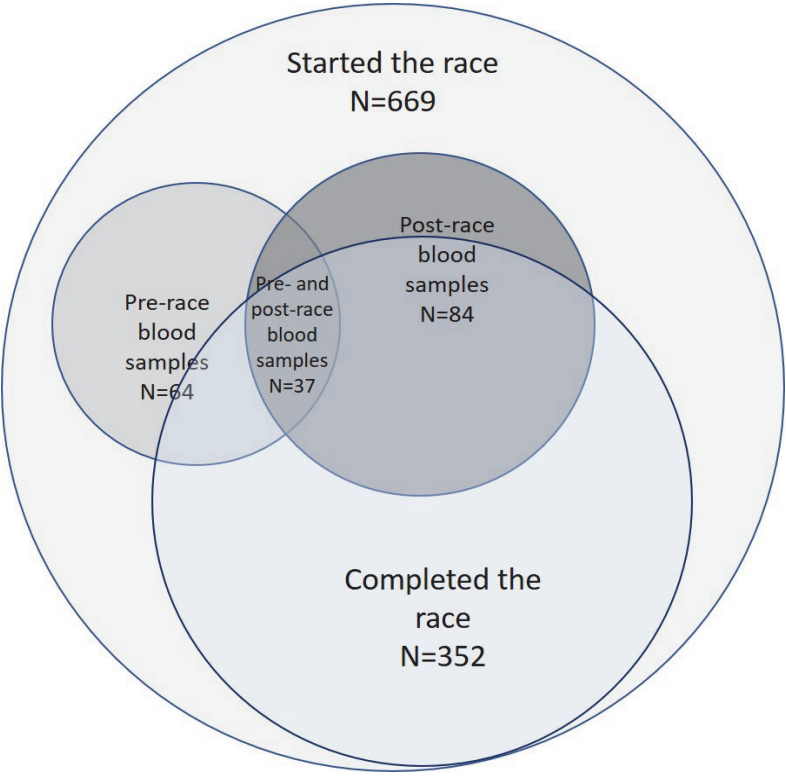

Figure 1. Venn diagram of the race and study participants. pre- and post-race blood samples from 37 runners.

Of the 84 runners whose blood samples were collected after the race, 18 did not successfully complete the race (Table 1 and Fig. 1). Of the 37 runners who provided us with pre- and post-race samples, the mean serum $\left[\mathrm{Na}^{+}\right]$levels decreased (Table 2 and Figure 2) from $138.4 \pm 1.7 \mathrm{mmol} /$ $\mathrm{L}$ (range; $134-142 \mathrm{mmol} / \mathrm{L}$ ) to $135.8 \pm 3.0 \mathrm{mmol} / \mathrm{L}$ (range; $131-141 \mathrm{mmol} / \mathrm{L})(p<0.001)$.

The mean post-race $\left[\mathrm{Na}^{+}\right]$level (Table 3 and Figure 2) of all 84 runners was $136.4 \pm 2.7 \mathrm{mmol} / \mathrm{L}$ (range; 129-143 $\mathrm{mmol} / \mathrm{L})$.

Of the 84 runners with post-race samples, $17(20 \%)$ had EAH (Table 4). On average, finishers lost $0.84 \%$ (standard deviation $\pm 2.34 \%$ ) of their weight after completing the race. Table 4 summarizes the association between individual variables and the incidence of EAH.

None of the runners in the study reported any symptoms after the race through our post-race electronic survey (92\% response rate). The binary multiple logistic regression showed that only post-race serum CK levels were significantly correlated with the incidence of EAH. We also found that there was no association between the average months of

Table 2. Changes in the serum electrolyte levels of 37 runners before and after the race.

\begin{tabular}{|cccc} 
Laboratory (RR) & $\begin{array}{c}\text { Pre-race mean } \pm \text { SD } \\
\text { (range) }\end{array}$ & $\begin{array}{c}\text { Post-race mean } \pm \text { SD } \\
\text { (range) }\end{array}$ & $\begin{array}{c}p \text { value } \\
\text { (Wilcoxon) }\end{array}$ \\
\hline Sodium (135-145 mmol/L) & $138.4 \pm 1.7(134-142)$ & $135.8 \pm 3.0(131-141)$ & $0.000^{*}$ \\
\hline Potassium (3.5-5.1 mmol/L) & $4.3 \pm 0.4(3.8-5.4)$ & $4.1 \pm 0.4(3.4-5)$ & 0.069 \\
\hline Chloride (98-108 mmol/L) & $103.9 \pm 1.7(100-107)$ & $100.5 \pm 3.7(94-108)$ & $0.000^{*}$ \\
\hline Carbon dioxide $(21-31 \mathrm{mmol} / \mathrm{L})$ & $27.1 \pm 1.9(23-32)$ & $24.4 \pm 3.0(17-30)$ & $0.000^{*}$ \\
Calcium $(8.6-10.3 \mathrm{mg} / \mathrm{dL})$ & $9.8 \pm 0.3(9.0-10.4)$ & $9.6 \pm 0.4(8.7-10.3)$ & $0.047^{*}$ \\
\hline
\end{tabular}

$\mathrm{RR}$, reference range; SD, standard deviation; *statistically significant but clinically non-significant changes.

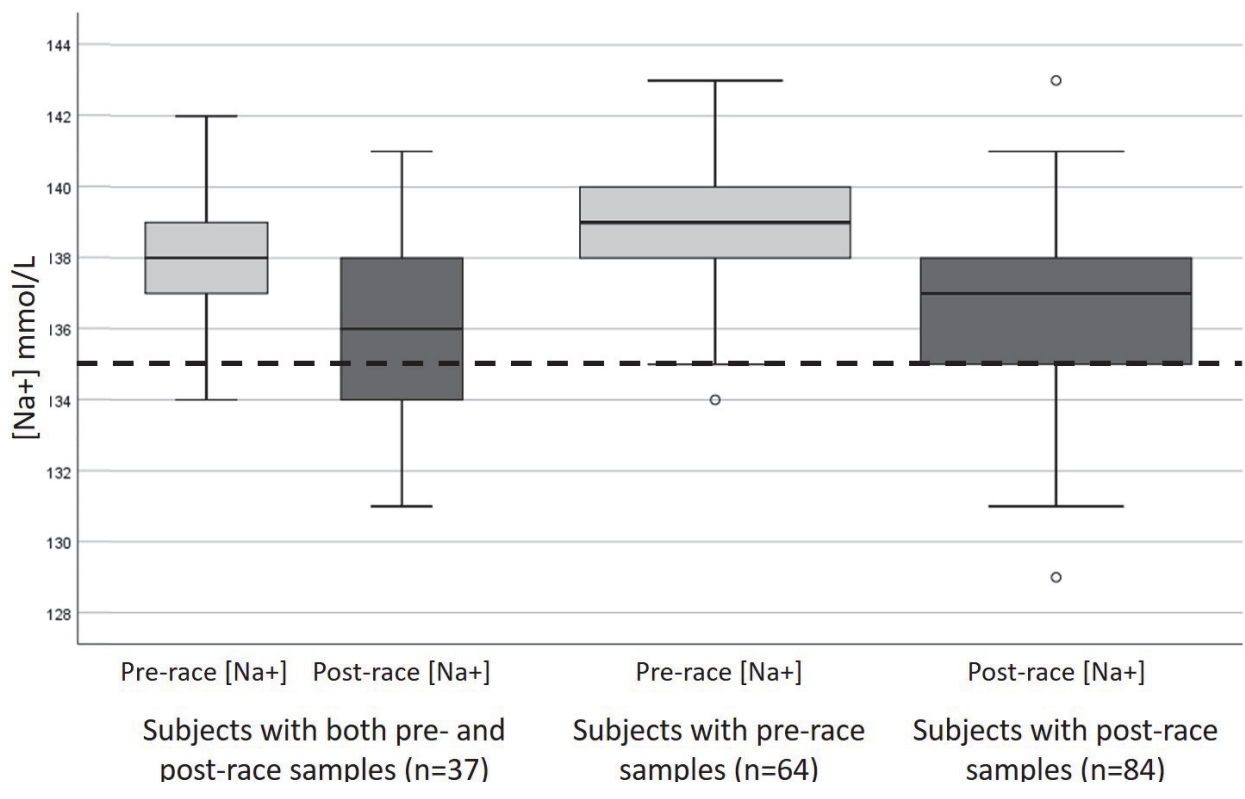

Figure 2. Box plot of the serum sodium $\left[\mathrm{Na}^{+}\right]$levels among runners with both pre- and post- race samples, runners with pre-race samples, and runners with post-race samples. 
training and previous attempts (successful or unsuccessful) to complete any $161-\mathrm{km}$ ultramarathons and the incidence of EAH. The incidence of EAH in the univariable logistic regression was higher among female than among male runners $(40 \%$ vs. $16 \% ; p<0.05)$ (Table 4$)$. However, this minor difference disappeared $(p=0.066)$ when binary multiple logistic regression analyses were performed (Table 4). There was a linear correlation between lower $\left[\mathrm{Na}^{+}\right]$levels and higher $\mathrm{CK}$ levels post-race $\left(\mathrm{R}^{2}=0.1, p<0.005\right)$, which has been published elsewhere ${ }^{21}$. Only two runners had potassium $\left(\left[\mathrm{K}^{+}\right]\right)$levels beyond the reference range $(3.4 \mathrm{mmol} / \mathrm{L}$ and $5.2 \mathrm{mmol} / \mathrm{L}$ ) post-race (Table 5).

The means and ranges of other electrolytes post-race among the runners are summarized in Table 5. Results from other blood and urine tests are reported in detail in our pre- vious studies ${ }^{20-23}$. Based on the electronic survey conducted 1-2 weeks after the race, none of the athletes whose blood samples were collected visited an emergency department or a physician's office after the race.

\section{DISCUSSION}

Our data indicated that the incidence of EAH was lower than anticipated based on previous reports ${ }^{16}$. As mentioned in the Introduction, in another study conducted at a high altitude, 11 well-trained high-altitude natives (born, raised, and trained at 2,600 m) participated in two standard distance marathons $(42.2 \mathrm{~km})$, one at a high altitude $(2,650 \mathrm{~m})$, and the other at a low altitude $(470 \mathrm{~m})^{16}$. In the high altitude

Table 3. Serum electrolyte levels of 84 runners after the race.

\begin{tabular}{|cccc}
\hline Laboratory (RR) & Mean \pm SD & Range & Number of runners with out-of-range levels \\
\hline Sodium (135-145 mmol/L) & $136.4 \pm 2.7$ & $129-143$ & 17 below the RR $(20.2 \%)$ \\
\hline Potassium $(3.5-5.1 \mathrm{mmol} / \mathrm{L})$ & $4.1 \pm 0.4$ & $3.4-5.2$ & 1 below $(1.2 \%)$ and 1 above the $\mathrm{RR}(1.2 \%)$ \\
Chloride $(98-108 \mathrm{mmol} / \mathrm{L})$ & $101.0 \pm 3.4$ & $93-108$ & 10 below the RR $(11.9 \%)$ \\
Carbon dioxide $(21-31 \mathrm{mmol} / \mathrm{L})$ & $24.2 \pm 2.9$ & $17-30$ & 9 below the RR $(10.7 \%)$ \\
Calcium $(8.6-10.3 \mathrm{mg} / \mathrm{dL})$ & $9.7 \pm 0.4$ & $8.7-10.8$ & 6 above the RR $(7.1 \%)$ \\
\hline
\end{tabular}

$\mathrm{RR}$, reference range; SD, standard deviation.

Table 4. Relative risk estimates predicting exercise-associated hyponatremia $(n=17)$ among 84 runners after the race.

\begin{tabular}{|c|c|c|c|c|}
\hline & $\begin{array}{l}\text { Participants } \\
\text { with EAH } \\
(n=17)\end{array}$ & $\begin{array}{l}\text { Participants } \\
\text { without EAH } \\
\qquad(n=67)\end{array}$ & $\begin{array}{c}\text { Significance ( } p \text {-value) } \\
\text { of univariable logistic } \\
\text { regression }^{\dagger}\end{array}$ & $\begin{array}{l}\text { Significance ( } p \text {-value) of } \\
\text { binary multiple logistic } \\
\text { regression }\end{array}$ \\
\hline Age (year); mean \pm SD & $43.1 \pm 8.4$ & $41.8 \pm 9.2$ & 0.582 & 0.391 \\
\hline Sex; $n(\%)$ & & & $0.039^{*}$ & 0.066 \\
\hline Male & $11(15.9)$ & $58(84.1)$ & & \\
\hline Female & $6(40.0)$ & $9(60.0)$ & & \\
\hline BMI $\left(\mathrm{kg} / \mathrm{m}^{2}\right) ;$ mean \pm SD & $22.3 \pm 1.8$ & $22.9 \pm 2.2$ & 0.564 & 0.691 \\
\hline Race completion status; n (\%) & & & 0.836 & 1.000 \\
\hline Finished & $13(19.7)$ & $53(80.3)^{*}$ & & \\
\hline Did not finish & $4(22.2)$ & $14(77.8)$ & & \\
\hline $\begin{array}{l}\text { Race completion time (h:min); } \\
\text { mean } \pm \text { SD }\end{array}$ & $27: 33 \pm 2: 10$ & $27: 42 \pm 1: 52$ & 0.635 & 0.389 \\
\hline $\begin{array}{l}\text { Percentage of weight change only } \\
\text { among finishers } \pm S D\end{array}$ & $-0.33 \pm 1.71$ & $-1.56 \pm 2.15$ & 0.148 & 0.083 \\
\hline $\begin{array}{l}\text { Use of NSAIDs 1-2 days before the } \\
\text { race }\end{array}$ & $0(0.0)$ & $16(100.0)$ & $0.024^{*}$ & 0.999 \\
\hline Use of NSAIDs during the race & $3(17.6)$ & $14(82.4)$ & 0.745 & 0.965 \\
\hline Post-race CK (U/L); mean \pm SD & $21,890 \pm 24,665$ & $11,028 \pm 10,570$ & $0.000^{*}$ & $0.039^{*}$ \\
\hline $\begin{array}{l}\text { Post-race urine specific gravity } \\
\text { mean } \pm \text { SD }\end{array}$ & $5.1 \pm 1.8$ & $4.8 \pm 1.8$ & 0.551 & 0.347 \\
\hline
\end{tabular}

SD, standard deviation; BMI, body mass index; NSAIDs, nonsteroidal anti-inflammatory drugs; CK, creatine kinase; * ${ }^{*}$ statistically significant; ${ }^{\dagger}$ used $x^{2}$ for categorical variables and non-parametric test (Mann-Whitney $U$ test) for continuous variables; $€$ specific gravity was categorized as $1=1.000,2=1.005,3=1.010,4=1.015,5=1.020$, $6=1.025,7=1.030$.

Table 5. Post-race serum electrolyte levels of finishers vs. non-finishers $(n=84)$

\begin{tabular}{cccc} 
Laboratory (RR) & Finishers mean \pm SD (n=66) & Non-finishers mean \pm SD (n=18) & $p$-value (Mann-Whitney U test) \\
\hline Sodium (135-145 mmol/L) & $136.4 \pm 2.6$ & $136.3 \pm 2.9$ & 0.882 \\
\hline Potassium (3.5-5.1 mmol/L) & $4.0 \pm 0.3$ & $4.3 \pm 0.4$ & $0.003^{*}$ \\
Chloride (98-108 mmol/L) & $100.9 \pm 3.3$ & $101.1 \pm 3.6$ & 0.926 \\
Carbon dioxide (21-31 mmol/L) & $23.8 \pm 2.7$ & $25.4 \pm 3.2$ & $0.024^{*}$ \\
Calcium (8.6-10.3 mg/dL) & $9.7 \pm 0.4$ & $10.0 \pm 0.4$ & $0.003^{*}$
\end{tabular}

RR, reference range; SD, standard deviation; * statistically significant but clinically non-significant differences. 
marathon, the mean post-race serum $\left[\mathrm{Na}^{+}\right]$for the entire cohort was $131.7 \mathrm{mmol} / \mathrm{L}$ (pre-race $144.3 \mathrm{mmol} / \mathrm{L}$ ), whereas after the low altitude marathon, the post-race $\left[\mathrm{Na}^{+}\right]$was $144.7 \mathrm{mmol} / \mathrm{L}$ (pre-race $142.9 \mathrm{mmol} / \mathrm{L})^{16}$. The authors of that study originally hypothesized that dysnatremia might occur from enhanced renal water and $\left[\mathrm{Na}^{+}\right]$excretion as a physiological adaptation to high altitude and hypothesized it as a potential risk factor in their study ${ }^{16}$.

In the current study, only $20 \%$ of the 84 runners tested at the end of the race were biochemically diagnosed with hyponatremia (serum $\left[\mathrm{Na}^{+}\right]<135 \mathrm{mmol} / \mathrm{L}$ ). In our study, the $20 \%$ incidence of asymptomatic EAH was lower than the incidence of EAH reported after other ultramarathon races conducted closer to the sea level. For example, Seal et al. ${ }^{24}$ documented a $65 \%$ incidence of EAH after a $246 \mathrm{~km}$ race, whereas Lebus et al. ${ }^{25}$ confirmed that $51.2 \%$ of 45 race finishers developed asymptomatic EAH by the end of the race. Additionally, Cairns et al. ${ }^{26}$ demonstrated that $66.7 \%$ of 15 participants developed asymptomatic EAH at some point during an ultramarathon (and continued running), whereas only $26.7 \%$ of these runners had post-race EAH. Another study investigating EAH at high altitude $(2,780 \mathrm{~m})$ in ultramarathon $(44 \mathrm{~km})$ runners documented an $8 \%$ (5/62 runners) incidence of biochemical EAH at the end of the race ${ }^{27}$. Thus, it appears that altitude alone is not a pathogenic risk factor in the development of EAH and that other factors, such as high temperature ${ }^{24-26,28}$ and overdrinking ${ }^{4}$, are likely to have greater pathophysiological significance in the pathogenesis of EAH.

The current results also identified female sex and NSAID ingestion as risk factors for the development of EAH in our asymptomatic cohort. Female sex has been widely speculated to be a risk factor for the development of severe consequences of $\mathrm{EAH}^{6,8}$. However, another study clarified that women were at greater risk for developing dilutional hyponatremia, primarily due to their smaller body mass index and slower race times ${ }^{29}$. Additionally, although one study has confirmed that NSAIDs augment fluid retention during exercise ${ }^{30}$, data directly implicating NSAIDs in the development of EAH remain conflicted ${ }^{4}$ and are more likely to represent a permissive factor of overdrinking.

The runners in the current cohort who developed EAH also lost the least body weight $(-0.33 \mathrm{~kg})$ compared with runners who did not develop EAH $(-1.56 \mathrm{~kg})$, although this difference was not statistically significant $(p=0.08)$. This trend towards maintaining body weight (rather than losing weight during a $161-\mathrm{km}$ run) suggests that overdrinking with or without fluid retention was likely to contribute towards $\mathrm{EAH}^{4}$ while also highlighting the difficulties of using body weight as an accurate surrogate measure of natremia in longer races ${ }^{31}$.

Notably, no significant difference in serum $\left[\mathrm{Na}^{+}\right]$was documented between finishers and non-finishers. The incidence of EAH in non-finishers is largely unknown, as biochemical testing during races remains logistically problematic. Only Cairns et al. have been able to measure serum $\left[\mathrm{Na}^{+}\right]$during an ultramarathon race. Although Cairns et al. discovered that $66.7 \%$ of their small cohort became hypona- tremic at least once during (or immediately following) the ultramarathon race, their entire cohort managed to complete the event. Future studies should investigate serum electrolyte derangements in non-finishers along the course to more fully evaluate whether EAH is a risk factor for dropping out of races.

The current study also assessed changes in other ions, ( $\left[\mathrm{K}^{+}\right]$, chloride, and carbon dioxide $\left[\mathrm{CO}_{2}\right]-$ a surrogate measure for bicarbonate) thought to contribute to osmotic equilibrium ${ }^{32}$, as well as the divalent cation, calcium $/\left[\mathrm{Ca}^{2+}\right]$, to assess possible overall dilution of ions within the vascular space. Although natremia mathematically drives osmotic equilibrium ${ }^{33}$, the contribution of other monovalent ions to actual clinical sequelae remains underexplored. Curiously, we found that race finishers demonstrated a decrease in all ions (Table 2), which would hypothetically represent an overall dilution within the vascular space rather than selective electrolyte depletion through sweat ${ }^{34}$. We also found that non-finishers demonstrated significant increases in serum $\left[\mathrm{K}^{+}\right],\left[\mathrm{Ca}^{2+}\right]$, and $\left[\mathrm{CO}_{2}\right]$ than race finishers (Table 5). These extracellular ionic changes (beyond highly regulated natremia changes) between finishers and non-finishers require further pathophysiological and clinical clarification in the future ${ }^{15}$.

Future studies should also investigate the incidence of EAH in high-altitude races between natives of high- and low-altitude areas, which may partially explain the differences between our results (largely non-natives) vs. those of Schmidt et al. (high-altitude natives) ${ }^{16}$. Although none of the participants with EAH in the present study were symptomatic, the potential differences between severe symptomatic $\mathrm{EAH}^{9}$ and acute mountain sickness ${ }^{19}$ warrant further investigation because there is the potential for overlap and misdiagnosis between the two potentially fatal entities ${ }^{35}$.

Our study has several limitations. First, as this was an observational study, we could not make a definitive statement on the causality of the abnormal results. Second, using a convenient sample size, we may have an underpowered sample. However, we were able to recruit a considerable number of participants (including drop-outs) compared with previous studies. Third, as we did not measure the hemoglobin and hematocrit, we were unable to calculate the plasma volume, which may have some potential effects on the serum $\left[\mathrm{Na}^{+}\right]$level. Fourth, we did not possibly account for certain unknown confounders. Fifth, as we were unable to measure the runners' fluid and electrolyte intake, this may have affected the results of serum electrolytes. Finally, because every ultramarathon race is unique, we cannot completely extrapolate these results to other races.

In summary, we found that the incidence of EAH was lower in this ultramarathon than that reported in previous studies. We believe this is possibly due to the relatively cooler temperatures during this race compared with similar races. There was also a significant difference in EAH between the sexes, which was no longer significant in the multiple logistic regression analyses. The effect of altitude on EAH appears to be minimal; however, it warrants further investigation with larger cohorts, a more critical assessment 
of natives vs. non-natives, and acclimatization status. We recommend that ultramarathon medical teams establish a protocol to assess the feasibility and usefulness of measuring serum $\left[\mathrm{Na}^{+}\right]$levels in suspected athletes, particularly at the finish line for each specific race ${ }^{36,37}$.

\section{ACKNOWLEDGEMENTS}

We would like to thank the Leadville Race Series, Lifetime Fitness, Dr. John C. Hill, and the study participants. This study was funded in part by the ACSM Clinical Sports Medicine Endowment Grant.

\section{REFERENCES}

1. Khodaee M, Ansari M. Common ultramarathon injuries and illnesses: race day management. Curr Sports Med Rep. 2012;11:290-7.

2. Scheer V. Participation trends of ultra endurance events. Sports Med Arthrosc Rev. 2019;27:3-7.

3. Hew-Butler T, Loi V, Pani A, Rosner MH. Exercise-associated hyponatremia: 2017 update. Front Med (Lausanne). 2017;4:21.

4. Hew-Butler T, Rosner MH, Fowkes-Godek S, Dugas JP, Hoffman $M D$, Lewis DP, Maughan RJ, Miller KC, Montain SJ, Rehrer NJ, Roberts WO, Rogers IR, Siegel AJ, Stuempfle KJ, Winger JM, Verbalis JG. Statement of the 3rd international exercise-associated hyponatremia consensus development conference, Carlsbad, California, 2015. Br J Sports Med. 2015;49:1432-46.

5. Bennett BL, Hew-Butler T, Rosner MH, Myers T, Lipman GS Wilderness medical society clinical practice guidelines for the management of exercise-associated hyponatremia: 2019 update. Wilderness Environ Med. 2020;31:50-62.

6. Hew TD, Chorley JN, Cianca JC, Divine JG. The incidence, risk factors, and clinical manifestations of hyponatremia in marathon runners. Clin J Sport Med. 2003;13:41-7.

7. Knechtle B, Chlibkova D, Papadopoulou S, Mantzorou M, Rosemann T, Nikolaidis PT. Exercise-associated hyponatremia in endurance and ultra-endurance performance-aspects of sex, race location, ambient temperature, sports discipline, and length of performance: a narrative review. Medicina (Kaunas). 2019;55:537.

8. Ayus JC, Varon J, Arieff Al. Hyponatremia, cerebral edema, and noncardiogenic pulmonary edema in marathon runners. Ann Intern Med. 2000;132:711-4.

9. Spano SJ, Reagle Z, Evans T. Symptomatic hypotonic hyponatremia presenting at high altitude. Wilderness Environ Med. 2014;25:69-74.

10. Page AJ, Reid SA, Speedy DB, Mulligan GP, Thompson J. Exercise-associated hyponatremia, renal function, and nonsteroidal antiinflammatory drug use in an ultraendurance mountain run. Clin J Sport Med. 2007;17:43-8.

11. Knechtle B, Chlibkova D, Nikolaidis PT. Exercise-associated hyponatremia in endurance performance. Praxis (Bern 1994). 2019;108:615-32.

12. Speedy DB, Noakes TD, Rogers IR, Thompson JM, Campbell RG, Kuttner JA, Boswell DR, Wright S, Hamlin M. Hyponatremia in ultradistance triathletes. Med Sci Sports Exerc. 1999;31:809-15.

13. Danz M, Pottgen K, Tonjes PM, Hinkelbein J, Braunecker S. Hy- ponatremia among triathletes in the ironman European championship. N Engl J Med. 2016;374:997-8.

14. Khodaee M, Luyten D, Hew-Butler T. Exercise-associated hyponatremia in an ultra-endurance mountain biker: a case report. Sports Health. 2013:5:334-6.

15. Hew-Butler T, V.G. S-H, Sabou J. Exercise-associated electrolyte disorders. Curr Opin Endocr Metab Res. 2019;9:51-5.

16. Schmidt W, Rojas J, Boning D, Bernal H, Garcia S, Garcia O. Plasma-electrolytes in natives to hypoxia after marathon races at different altitudes. Med Sci Sports Exerc. 1999;31:1406-13.

17. Hew-Butler T, Noakes TD, Soldin SJ, Verbalis JG. Acute changes in arginine vasopressin, sweat, urine and serum sodium concentrations in exercising humans: does a coordinated homeostatic relationship exist? Br J Sports Med. 2010;44:710-5.

18. Mellor AJ, Boos CJ, Ball S, Burnett A, Pattman S, Redpath M, Woods DR. Copeptin and arginine vasopressin at high altitude: relationship to plasma osmolality and perceived exertion. Eur J Appl Physiol. 2015;115:91-8.

19. Ayus JC, Moritz ML. Exercise-associated hyponatremia masquerading as acute mountain sickness: are we missing the diagnosis? Clin J Sport Med. 2008;18:383-6.

20. Khodaee M, Saeedi A, Irion B, Spittler J, Hoffman MD. Proteinuria in a high-altitude 161-km (100-mile) ultramarathon. Phys Sportsmed. 2021;49:92-9.

21. Magrini D, Khodaee M, San-Millan I, Hew-Butler T, Provance AJ. Serum creatine kinase elevations in ultramarathon runners at high altitude. Phys Sportsmed. 2017;45:129-33.

22. Tirabassi JN, Olewinski L, Khodaee M. Variation of traditional biomarkers of liver injury after an ultramarathon at altitude. Sports Health. 2018;10:361-5.

23. Khodaee M IB, Spittler J. Saeedi A. Hoffman MD. Characteristics of runners meeting acute kidney injury criteria following a 161-km ultramarathon at high altitude. Trans/ Sports Med. 2021;Published online ahead of print.

24. Seal AD, Anastasiou CA, Skenderi KP, Echegaray M, Yiannakouris $\mathrm{N}$, Tsekouras YE, Matalas AL, Yannakoulia M, Pechlivani F, Kavouras SA. Incidence of hyponatremia during a continuous 246km ultramarathon running race. Front Nutr. 2019;6:161.

25. Lebus DK, Casazza GA, Hoffman MD, Van Loan MD. Can changes in body mass and total body water accurately predict hyponatremia after a 161-km running race? Clin J Sport Med. 2010;20:193-9

26. Cairns RS, Hew-Butler T. Incidence of exercise-associated hyponatremia and its association with nonosmotic stimuli of arginine vasopressin in the gnw100s ultra-endurance marathon. Clin J Sport Med. 2015;25:347-54.

27. Arnaoutis $G$, Anastasiou CA, Suh H, Maraki M, Tsekouras $Y$, Dimitroulis E, Echegaray M, Papamichalopoulou D, Methenitis S, Sidossis LS, Kavouras SA. Exercise-associated hyponatremia during the olympus marathon ultra-endurance trail run. Nutrients. 2020;12:997.

28. Lipman GS, Burns P, Phillips C, Jensen J, Little C, Jurkiewicz C, Jarrett B, Walker A, Mansfield N, Krabak BJ. Effect of sodium supplements and climate on dysnatremia during ultramarathon running. Clin J Sport Med. 2020; Published online ahead of print.

29. Almond CS, Shin AY, Fortescue EB, Mannix RC, Wypij D, Binstadt BA, Duncan CN, Olson DP, Salerno AE, Newburger JW, Greenes DS. Hyponatremia among runners in the Boston marathon. N Engl 
J Med. 2005;352:1550-6.

30. Walker RJ, Fawcett JP, Flannery EM, Gerrard DF. Indomethacin potentiates exercise-induced reduction in renal hemodynamics in athletes. Med Sci Sports Exerc. 1994;26:1302-6.

31. Tan DW, Yap SH, Wang M, Fan PW, Teo YS, Krishnasamy P, Krishna L, Hew-Butler T, Lee JK. Body mass changes across a variety of running race distances in the tropics. Sports Med Open. 2015;2:26.

32. Nguyen MK, Kurtz I. New insights into the pathophysiology of the dysnatremias: a quantitative analysis. Am J Physiol Renal Physiol. 2004;287:F172-80.

33. Edelman IS, Leibman J, O'Meara MP, Birkenfeld LW. Interrelations between serum sodium concentration, serum osmolarity and total exchangeable sodium, total exchangeable potassium and total body water. J Clin Invest. 1958:37:1236-56.

34. Baker LB, Wolfe AS. Physiological mechanisms determining eccrine sweat composition. Eur J Appl Physiol. 2020;120:719-52.

35. Gatterer H, Wille M, Faulhaber M, Lukaski H, Melmer A, Ebenbichler $\mathrm{C}$, Burtscher M. Association between body water status and acute mountain sickness. PLoS One. 2013;8:e73185.

36. Hoffman MD, Khodaee M, Nudell NG, Pasternak A. Recommendations on the appropriate level of medical support at ultramarathons. Sports Med. 2020;50:871-84.

37. Hoffman MD, Pasternak A, Rogers IR, Khodaee M, Hill JC, Townes DA, Scheer BV, Krabak BJ, Basset P, Lipman GS. Medical services at ultra-endurance foot races in remote environments: medical issues and consensus guidelines. Sports Med. 2014;44:105569. 